ISSN electrónico: 1885-5210

DOI: https://doi.org/10.14201/rmc20201611723

\title{
AMAR LA VIDA / WIT (2001); UN CASO DONDE EL ARTE DE CUIDAR APARECE DESDIBUJADO
}

\section{Wit (2001); a case where the art of caring appears blurrys}

\author{
Oscar BOTTASSO \\ Científicas y Técnicas), Rosario (Argentina). \\ e-mail: bottasso@idicer-conicet.gob.ar \\ Fecha de recepción: 2 de julio de 2019 \\ Fecha de aceptación: 2 de septiembre de 2019 \\ Fecha de publicación: 15 de marzo de 2020
}

Instituto de Inmunología Clínica y Experimental de Rosario (Universidad Nacional de Rosario-Consejo Nacional de Investigaciones

\section{Resumen}

Versada como pocos en los sonetos metafísicos de John Donne y los intrincados vericuetos de la dupla vida y muerte, Vivian Bearing debe enfrentarse de buenas a primeras a un cáncer de ovario avanzado. Inmersa en una vida académica jalonada de logros medulares en su existencia, la enfermedad irrumpe intempestivamente y la traspone desde aquella zona de confort al terreno de las incertidumbres donde los hechos se rigen por designios ajenos a nuestros deseos y especulaciones racionales. Como un aprendizaje física y mentalmente doloroso, la protagonista va tomando conciencia de su enfermedad, el destrato de los médicos para con ella, a la par de efectuar un examen de las decisiones adoptadas a lo largo de sus años, su relación con los demás y la dura lección de empezar a descubrir que ante el momento más trascendente del acontecer humano el andamiaje teórico y su lógica más refinada son insuficientes.

Palabras clave: cáncer; ensayo clínico; cuidados paliativos; bioética; poesía; música.

\section{Summary}

As proficient as few in John Donne's metaphysical sonnets and the intricate twists of life and death, Vivian Bearing must confront an advanced ovarian cancer. Immersed in an academic life marked by pivotal achievements through- out her existence, the disease breaks out untimely moving her from that comfort zone to the field of uncertainties where facts are governed by arranges external to our goals and rational judgements. As a physical and mentally painful learning, the protagonist is becoming aware of her illness, the disappointing way physicians deal with her, in parallel to reviewing decisions taken throughout her years, and the relationship with people. Also, the hard lesson of beginning to realize that when facing the most transcendental instance of human life, the theoretical background and its more sophisticated logic become insufficient.

Key words: cancer; clinical trial; palliative care; bioethics; poetry; music. 


\section{AMAR LA VIDA / WIT (2001); UN CASO DONDE EL ARTE DE CUIDAR APARECE DESDIBUJADO OSCAR BOTTASSO}

\section{Ficha Técnica}

Título: Amar la vida.

Título original: Wit.

País: EEUU.

Año: 2001.

Director: Mike Nicholls.

Música: Spiegel im Spiegel de Arvo Pärt, y segundo movimiento de la 3ra sinfonía de Henryk Gorecki. Breve incursión al adagio del cuarteto para cuerdas de Dmitri Shostakovich y la pregunta no contestada de Charles Ives.

Fotografía: Seamus McGarvey.

Guión: Margaret Edson y Emma Thompson; basado en la obra de Margaret Edson.

Intérpretes: Emma Thompson (Vivian Bearing), Christopher Lloyd (Dr. Harvey Kelekian), Eileen Atkins (Evelyn Ashford), Audra McDonald (Susie Monahan), Jonathan Woodward (Dr. Jason Posner), Harold Pinter (padre de Vivian), Rebecca Laurie (Vivian a los 5 años), Su Lin Looi (Enfermera, como Su-Lin Looi), Raffaello Degruttola (1er técnico), Miquel Brown (2do técnico), Hari Dhillon (1er residente), Benedict Wong (2do residente), Alex Gregor (3er residente), Lachele Carl (4to residente), ...

Color: color.

Duración: 125 minutos.

Género: drama.

Sinopsis: Vivian Bearing es doctora en filosofía, reconocida y admirada experta en literatura y poesía inglesa del Siglo XVII, cuya eximia carrera universitaria se ve penosamente troncada por la aparición de una neoplasia muy agresiva. Aquella mujer abocada a su trabajo, con escasas relaciones extraprofesionales está prácticamente sola en la vida para vérselas con tamaña enfermedad. La profesora aprende a convivir con su padecimiento, y descubre la deshumanización de las prácticas médicas donde sólo la enfermera a cargo del cuidado demuestra su lado humano y empatía para con la persona sufriente. Las circunstancias por las que atraviesa la llevan a replantearse el modo en que ha vivido y el peso relativo del pensamiento erudito en cuestiones vivenciales.

Productor: Simon Bosanquet

Enlaces:

https://www.youtube.com/watch?v=ZwN3Z74sQwo https://gloria.tv/video/6CCVpZL9dHoVCzZqbB pVoWErH
Trailer

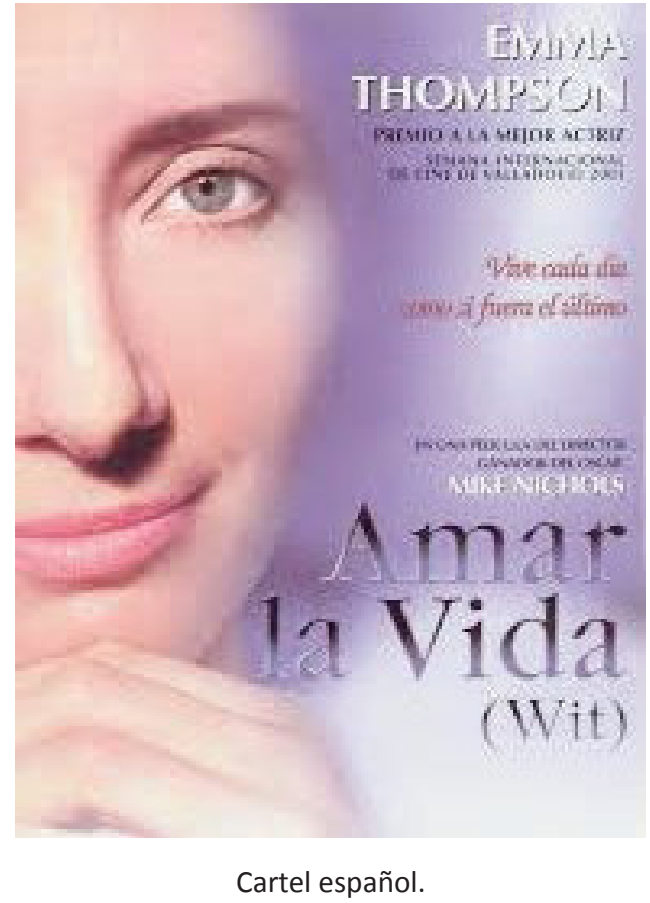

Si la medicina no es objetiva, es imposible si la medicina es sólo una ciencia objetiva es inhumana ${ }^{1}$.

\section{La trama}

A modo de veredicto, la película arranca con una exposición diagnóstica por parte del doctor Kelekian quien le anuncia a Vivian la presencia de un cáncer de ovario avanzado. Todo dicho con serenidad y hasta casi desparpajo, desprovisto de cualquier carga afectiva o dejo de prudencia en lo que se comunica. Lejos de quebrarse Vivian recoge el guante gracias a su gran capacidad de discernimiento. Traspasada la noticia, Kelekian le propondrá la utilización de un tratamiento de momento en estudio y aún no aprobado, el cual sería adecuado para su padecimiento, y permitiría a su vez lograr un mejor conocimiento en torno a la enfermedad.

Socarronamente y sin golpes bajos, Vivian mira la cámara y refiere en primera persona las experiencias hospitalarias donde es sometida a las sesiones de 
quimioterapia y el duro aprendizaje que ello acarrea (Foto 1). Si bien se trata de una enfermedad con muy mal pronóstico su doctorado en filosofía, abultado conocimiento en los sonetos metafísicos de John Donne, y asuntos de vida y muerte harán las veces de salvoconducto como para salir airosa de la contienda. Siempre puso el cuerpo a los desafíos; y este sería uno más de los tantos. Una y otra vez insistirá en que ella es una autoridad en literatura inglesa, cuyos aportes al conocimiento de esta temática le han valido el reconocimiento de sus alumnos y colegas.

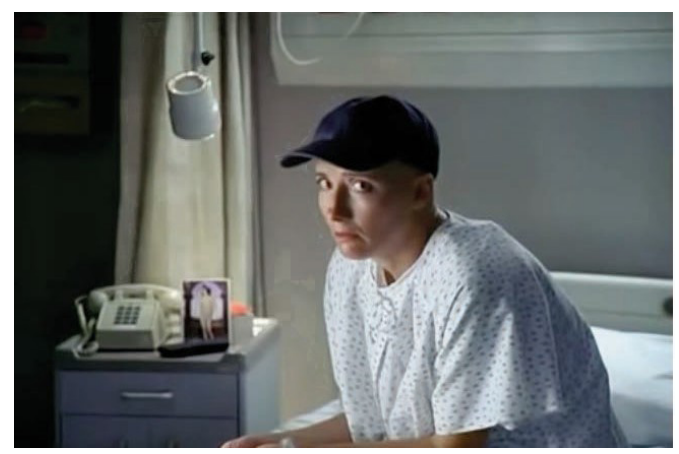

Foto 1. Desde su habitación narra las peripecias por las que atraviesa.

Sobreviene la escena con la profesora Ashford, en los comienzos de su carrera (Foto 2); quien además de la muy aguda observación respecto al análisis sobre el soneto de John Donne, le sugiere que utilice su inteligencia, se aboque menos a los textos y pase más tiempo con los amigos; consejo que Vivian desatiende. La melodía del Spiegel im Speigel se escucha por primera vez.

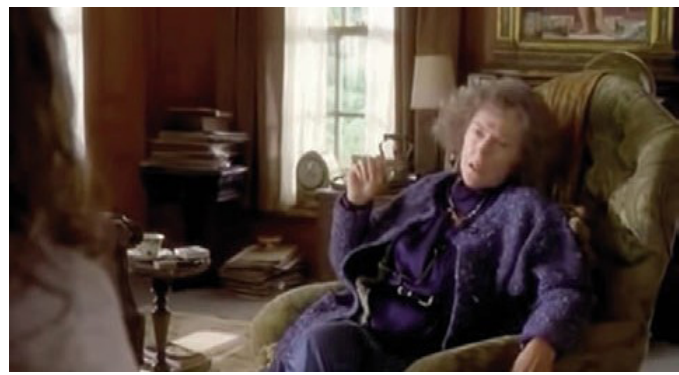

Foto 2. La entrevista con la Profesora Ashford en los comienzos de su carrera.
Se suceden dos escenas que ilustran perfectamente la dinámica del trabajo en tantas instituciones de salud: los estudios en el servicio de radiología y su primera entrevista con el residente Jason, otrora alumno suyo (Foto 3). El joven sigue el libreto a pie juntillas y sale prácticamente disparado tras realizar un examen ginecológico, que bien podría inscribirse en un acto de vejación en el sacrosanto nombre de la medicina. "Minuciosamente degradante» según lo describe Vivian; en medio de un sufrimiento expresado en frases como «si vomitara mi cerebro" o "el dolor es lo que hace que me sienta viva». Acto seguido, LA GRANDE MISE EN SCÈNE de la visita en equipo un viernes por la mañana; o del concurso entre pavos reales para dirimir quién lo es más. El paciente como mero objeto de investigación y campo de combate donde se confrontan los saberes, destrezas y sagacidades del buen sabueso; en el marco de un abordaje terapéutico circunscripto al acatamiento a raja tabla del protocolo instituido, y prácticamente deshumanizado. Gravita el cáncer y no quien lo padece; en un notorio imperio de la biología tumoral y el balance hídrico-salino, por sobre la dimensión psicológica y espiritual. La cuestión central serán los resultados de la medicación investigada en esa particular «unidad de análisis», u objeto de estudio poco visualizado como una persona sufriente y sola.

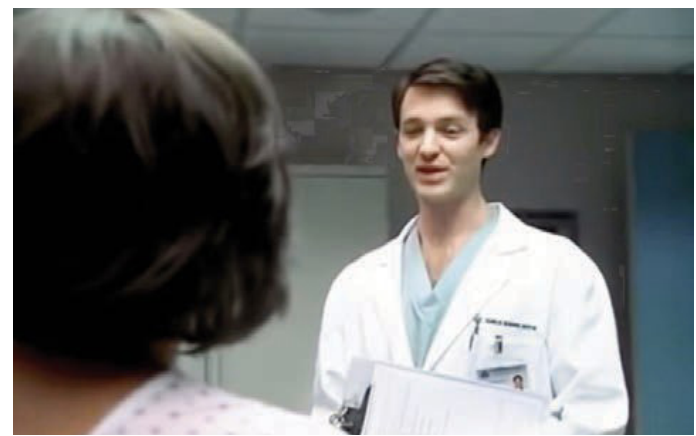

Foto 3. El primer encuentro con el residente Jason Posner.

En su afán de adquirir el vocabulario médico a modo de autodefensa, Vivian recuerda una anécdota con su padre en la primera infancia cuando aprende el significado de soporífero y a partir de allí su fascinación por las palabras. 
El episodio de neutropenia febril (Foto 4, en la sala de aislamiento) pone de relieve el apoyo de la enfermera desde las acciones concretas como el estar presente y saber comunicarse. Mientras Susie tiene plena conciencia de la frialdad del trato, Jason no hace más que seguir ajustándose a las pautas. Superada esa condición y de nuevo en el piso rememora sus clases sobre metafísica, la poesía de Donne y un poema que recitará al tiempo que le efectúan una ecografía. Intuye que su enfermedad sigue progresando. Aun así, Kelekian y los residentes están muy satisfechos puesto que ha completado todos los ciclos de quimioterapia a dosis máximas. Por sí o por no, en términos de éxitos terapéuticos, "knowledge has been gained». Se presenta Jason y cuando le pregunta por qué trabaja en cáncer el joven abandona las formalidades. Su pasión está en la fisiopatogenia del desarrollo tumoral y quizás algún día constituya un grupo de investigación a su cargo, como para confrontar con los clínicos, no conscientes de que lo crucial es la investigación. Al igual que ella Jason, ha dejado de lado el aspecto humano y tampoco está en condiciones de ofrecer ese costado tan necesario del cuidado médico; bastante parecido a su negativa cuando un estudiante le solicitara una prórroga para la entrega de un trabajo debido a la muerte de su abuela. Por un momento Vivian incluso se atreve a insinuarle un replanteo vivencial, ante lo cual Jason la interroga acerca de cómo está su sensorio. Aquel joven dotado de una gran capacidad científica está desposeído de las aptitudes imprescindibles para manejarse con pacientes; como suele decirse, bien poco de inteligencia emocional.

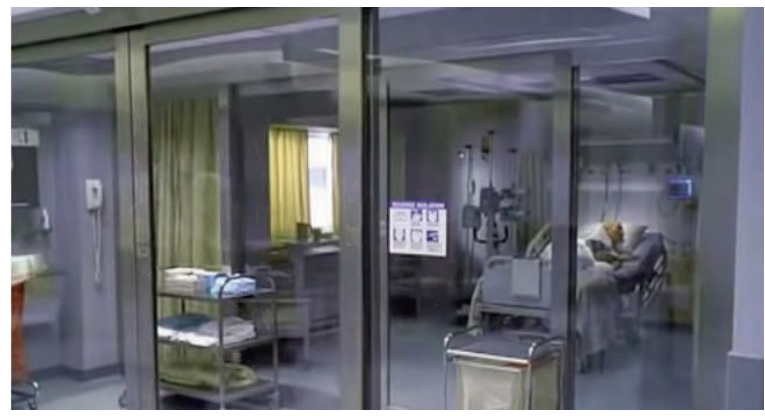

Foto 4. El aislamiento a raíz del episodio de neutropenia febril.
El miedo, la angustia y la incertidumbre se apoderan de ella. Susie se hace presente y trae dos helados que tomarán juntas (Fotos 5 y 6). En un diálogo impregnado de sensibilidad y entereza la enfermera le refiere que el cáncer ha aparecido en otros sitios; algo que Vivian presentía. Le pregunta si desea maniobras de resucitación en caso de presentar un paro cardíaco; ante lo cual le comunica su voluntad de no ser reanimada. Presa de la sensación de haberse vuelto chabacana, finalmente entiende que en un momento de tantas penurias la simpleza y la compasión revisten una jerarquía mucho mayor que las clarividencias intelectuales. Quizás no supo pedir o no se atrevió a manifestar el deseo de cualquier mortal a ser amado.

Sobrevuela una voz de soprano que entona la canción del segundo movimiento de la sinfonía de Gorecki, preparada a partir de una oración escrita por Helena Blazusiakówna encarcelada por la Gestapo en 1944.
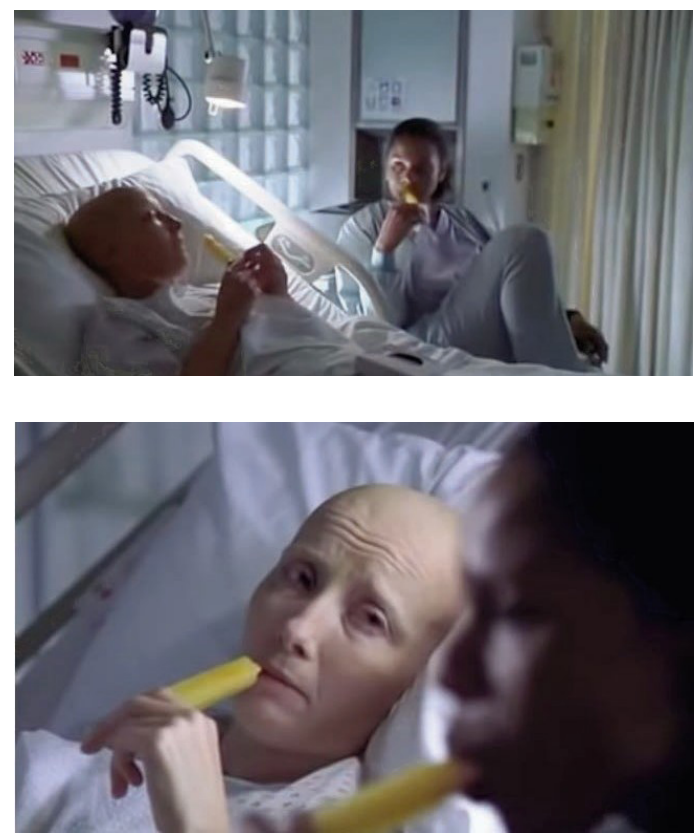

Fotos 5 y 6. En compañía de la enfermera Susie y compartiendo un helado.

Los dolores de Vivian son muy intensos y Kelekian indica morfina. Jason simplemente contempla la situación 
no sabe qué decir ni hacer; se refiere a ella y sus cualidades académicas, lo intrincado de la poesía de Donne, al igual que los experimentos del laboratorio. Casi sobre el final, la profesora Ashford viene a visitarla (Foto 7); y acurrucándola sobre sí le narra la historia del conejo fugitivo de Margaret W. Brown, cuya moraleja resalta que nadie puede huir de su condición. Se despide con el deseo de que coros de ángeles salgan a recibirla.

Jason advierte que Vivian está en paro y solicita el código azul de reanimación. En medio del revuelo entre

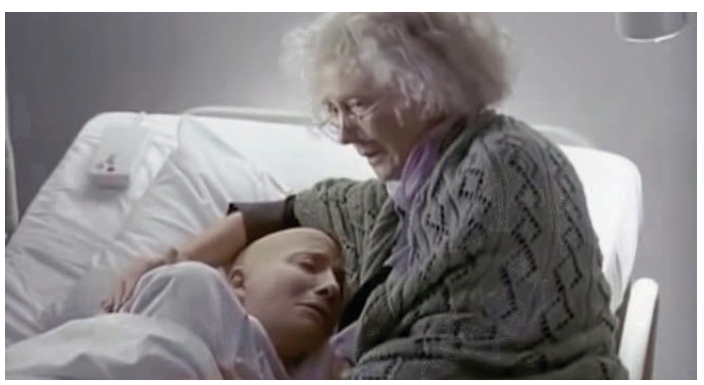

Foto 7. La visita de la Profesora Ashford.

resucitadores, Susie consigue hacerles entender que la decisión de Vivian no era esa. La enfermera cubre el cuerpo, consciente de la dignidad del ser humano. Como ningún otro capta la solemnidad del momento y la reflexión que impone ese paso tan trascendente de la persona humana.

Spiegel im Spiegel que en alemán indica espejo en el
espejo intenta representar esa infinidad de imágenes
conseguidas al enfrentar un cristal con el otro. Es una
de las obras más conocidas de Arvo Pärt, originalmente
escrita para piano y violín, posteriormente adaptada
para otros instrumentos como en este caso donde
la cuerda está a cargo del violonchelo. Un ejemplo
de música minimalista con ese rasgo distintivo del
compositor estonio: la música de «campanitas», o
«tintinnabuli»; de fuerte contenido expresivo y hasta
casi elegíaco. En tono de fa mayor el piano va tocando
tríadas de negras ascendentes mientras la cuerda
exhibe una línea melódica de ascenso y descenso,
con el agregado de una nota en cada uno de estos
pasos, a modo de perpetuación como los espejos
opuestos entre sí.

Spiegel im Spiegel que en alemán indica espejo en el conseguidas al enfrentar un cristal con el otro. Es una de las obras más conocidas de Arvo Pärt, originalmente escrita para piano y violín, posteriormente adaptada para otros instrumentos como en este caso donde la cuerda está a cargo del violonchelo. Un ejemplo intivo de nitas", o casi elegíaco. En tono de fa mayor el piano va tocando tríadas de negras ascendentes mientras la cuerda exhibe una línea melódica de ascenso y descenso, pasos, a modo de perpetuación como los espejos

\section{La práctica clínica desde la visión bioética}

En el core del acto médico alguien enfermo y como tal necesitado recurre a quien supone capaz y dispuesto a brindarle ayuda. En ese contexto pueden distinguirse cuanto menos tres elementos: el requerimiento del paciente, la debida competencia del clínico y el carácter profesional de la práctica que tendrá a lugar. El modo más fidedigno para evaluarla no sólo está determinado por la competencia médica sino también por cuestiones ético/ morales, que tomadas en conjunto procuran auxiliar al sufriente ${ }^{2-4}$.

Como las palabras no son inocentes, conviene detenernos a considerar un par de significados muy atingentes para el tema que nos ocupa. Cuidar proviene de "coidar» un sustantivo en desuso relacionado con "cogitāre» que significa pensar. El verbo denota una acción imbuida de atención, esfuerzo y dedicación. Por su parte, curar (también del latín; "curāre» por cuidar) implica mejorar, sanar, rehabilitar y recobrar la salud, pero está relacionado asimismo con cuidado o la preocupación/ocupación hacia algo o alguien. Pensemos por un momento en el párroco a quien se le ha encomendado precisamente la «cura» (cuidado) de las almas. Visto desde la medicina, vaya uno a saber cuándo sanar y curar pasaron a ser equiparables, mientras que el cuidar más entroncado con lo preventivo y afectivo se fue volviendo menos representativo.

Si rescatamos las significaciones, el cuidado con miras a la curación debería entonces afrontar no sólo la esfera física, sino también mental y espiritual, comprometidas por la enfermedad. $Y$ aun cuando la misma sea irreversible, sigue existiendo un espacio de contención para aliviar el dolor y el sufrimiento. Puede que la sanación sea una meta inalcanzable, pero nunca lo será el cuidado puesto que la ruptura se da a nivel corporal, psicológico y axiológico. Con ello preservaremos la dignidad de la persona; un fin en sí misma, cuyo valor es inherente y no determinado por su riqueza, educación o posición social. Lo que es bueno para el hombre no está sujeto a la construcción social, sino que reside dentro de la misma naturaleza humana.

Hallarse enfermo es igualmente un hecho existencial, por cuanto el padecimiento está íntimamente entroncado con la historia del paciente, y a la vez emerge como una 
oportunidad para reflexionar sobre el modo en que se ha estado viviendo ${ }^{5}$. A la par de la "res extensa», el paciente acarrea su "res cogitans» ${ }^{6}$ por lo que al referirse a su dolencia el relato no es meramente descriptivo, sino que está atravesado por sus creencias, temores, y dudas. En esa escucha el médico va descubriendo estructuras subyacentes que van mucho más allá de las simples palabras y deben sopesar a la hora de la toma de decisiones. Empatizar con la situación del paciente le otorga una plusvalía al sentido del cuidado. Visibilizar al «otro» refuerza nuestra condición de seres morales.

Como ya fuera muy bien explicitado 7 , la película muestra desde distintos ángulos la soledad de Vivian, ante una enfermedad que acabará con su vida. Una abundancia de recursos tecnológicos en ausencia de una actitud médica que la haga sentir acompañada y cuidada, aun cuando la expectativa de recuperación sea escasa ${ }^{7-9}$. Mal que nos pese los Kelekianes no son la excepción. Bien perceptibles en esto de hacer gala de su egocentrismo, falta de empatía y poco tacto sea para los pacientes como el equipo de salud; siempre oteando por encima y resguardado en un lenguaje técnico. Por su parte, la escena donde la paciente es informada y se le solicita su consentimiento se da de bruces, con las normas de la bioética. Vivian se somete a un tratamiento experimental, del cual aún no se ha demostrado su eficacia, amén de los efectos colaterales. El consentimiento es un proceso que lleva su tiempo y para que la decisión sea realmente autónoma el paciente debe tener ante sí todas las cartas sobre la mesa, a fin de justipreciar debidamente. El «firme aquí» satisface las cuestiones legales, pero no exime de las bribonadas que tarde o temprano golpearán a las puertas de la conciencia.

Una actitud genuinamente beneficente, requiere cultivar ciertas virtudes tales como honestidad, compasión y prudencia a fin de que las decisiones adoptadas sean las más adecuadas. Para ello el razonamiento causal y técnico como aproximación de las ciencias naturales a la medicina, es absolutamente válido. Al determinar las características de una enfermedad su génesis como así también en la adopción de pautas de control, nos apoyaremos en aspectos probabilísticos, fundamentos fisiopatógenicos y las herramientas intervencionistas surgidas de la investigación biomédica. Pero el razonamiento clínico supera al científico. Es necesario integrar lo teórico con lo práctico y finalmente ponderar en qué medida el andamiaje de conocimientos encaja con ese particular micromundo real ${ }^{10-11}$.

Si bien el pluralismo y multiculturalismo postmodernos le han restado una enorme cuota de fundamento para tal o cual discurso moral; desde el cuidado de la salud la relación enfermo-sanador sigue siendo un buen punto de partida. Como un mandato omnipresente, implícito o explícito «hacer el bien y evitar el mal» es un elemento central en la relación de curación, y la posibilidad de que el enfermo recupere su integridad. Nos basemos en la ley natural, la voluntad o los afectos, el acto benefícienle es una brújula que nos permite navegar en las agitadas aguas del escéptico relativismo ${ }^{2-4}$.

El modo en que se está llevando a cabo la práctica de la medicina en muchos centros de salud, da cuenta de la necesidad de un giro aperturista, encaminado a superar una suerte de status quo inexpugnable. Instituir una dimensión más "abrazadora» de cuidados médicos es una tarea ardua, que apunta a sumar sin apartarnos de lo alcanzado y consensuado como beneficioso. Si bien el desafío abunda en complejidad y plantea ciertos recelos, la empresa vale la pena puesto que a la postre la Medicina recuperará terreno en su humanización. Y aunque algunos lo consideraran una utopía, «imaginar lugares inexistentes», es el paso que antecede a cualquier concreción. Repasando las sabias reflexiones del Dante ${ }^{12}$, el sitio donde la esperanza es dejada de lado pertenece al infierno. Aspiremos pues, a una breve estancia en el purgatorio, cuanto menos.

Si la formación y el discernimiento moral logran posicionarse mejor habrá menos espacio para aquellas actitudes de las cuales hemos venido renegando: el interés de los grupos dominantes; el respeto puramente formal a las normas organizacionales; o bien la delegación de problemas éticos a la experiencia técnica, al ordenamiento jurídico y/o pautas de gestión.

Amar la vida y otras producciones cinematográficas por el estilo deberían constituir instancias formativas de la carrera de medicina. 


\section{AMAR LA VIDA / WIT (2001); UN CASO DONDE EL ARTE DE CUIDAR APARECE DESDIBUJADO OSCAR BOTTASSO}

\section{Referencias}

1. Buytendijk FJJ. (1959). Ned Tijdschr Geneeskd 103: 2504-8.

2. Pellegrino ED: The internal morality of clinical medicine: a paradigm for the ethics of the helping and healing professions. J Med Philos; 2001; 26(6):559-79.

3. Pellegrino ED. Toward a reconstruction of medical morality. Am J Bioeth 2006;6(2):65-71.

4. Bain LE. Revisiting the need for virtue in medical practice: a reflection upon the teaching of Edmund Pellegrino. Philos Ethics Humanit Med; 2018; 13(1):4.

5. Kottow AR, Kottow MH. The disease-subject as a subject of literature. Philos Ethics Humanit Med 2007, 2:(10).

6. Kenny A. Breve historia de la filosofía occidental. Buenos Aires: Paidos; 2006, p. 266-81.

7. Peña Bandrés I. Cuidados paliativos y cine: una actualización comentada de la producción relacionada desde mediados del siglo pasado hasta la última década del actual. Rev Med Cine 2018;14(4): 259-65.
8. Hofmann B. Expanding disease and undermining the ethos of medicine. Eur J Epidemiol 2019; 34(7): 613-9.

9. O'Mahony S. After the golden age: what is medicine for? Lancet 2019; 393 (10183): 1798-9.

10. Jochemsen $\mathrm{H}$, Hoogland J, Polder J. Maintaining integrity in times of scares resources. En: Viafora C, editor. Clinical Bioethics. A Search for the Foundations. Dordrecht: Springer; 2005, p. 139-52.

11. Dell'Oro R. Interpreting clinical judgment: epistemologica notes on the praxis of medicine. En: Viafora C, editor. Clinical Bioethics. A Search for the Foundations. Dordrecht: Springer; 2005, p. 155-67.

12. Alighieri D. La divina comedia. Infierno, Canto Tercero. Traducción en verso ajustada al original por Bartolomé Mitre. Nueva edición, definitiva autorizada dirigida por Nicolás Besio Moreno. Buenos Aires: Centro Cultural «Latium»; 1922, p. 15.

13. John Donne. Muerte no te enorgullezcas El Espejo Gótico. El Espejo Gótico (consultado el 20 de junio de 2019).

\begin{tabular}{|c|c|}
\hline Muerte no te enorgullezcas & Death Be Not Proud \\
\hline $\begin{array}{l}\text { Muerte, no te enorgullezcas, aunque algunos te hayan llamado } \\
\text { poderosa y terrible, no lo eres; } \\
\text { porque aquellos a quienes crees poder derribar } \\
\text { no mueren, pobre Muerte; y tampoco puedes matarme a mí. } \\
\text { El reposo y el sueño, que podrían ser casi tu imagen, brindan } \\
\text { placer, y mayor placer debe provenir de ti, } \\
\text { y nuestros mejores hombres se van pronto contigo, } \\
\text { idescanso de sus huesos y liberación de sus almas! } \\
\text { Eres esclava del destino, del azar, de los reyes y de los } \\
\text { desesperados, y moras con el veneno, la guerra y la enfermedad; } \\
\text { y la amapola o los hechizos pueden adormecernos tan bien } \\
\text { como tu golpe y mejor aún. ¿Por qué te muestras tan engreída, } \\
\text { entonces? } \\
\text { Después de un breve sueño, despertaremos eternamente y la } \\
\text { Muerte ya no existirá. iMuerte, tú morirás! }\end{array}$ & $\begin{array}{l}\text { Death be not proud, though some have called thee Mighty and } \\
\text { dreadful, for, thou art not so, } \\
\text { For, those, whom thou think'st, thou dost overthrow, Die not, } \\
\text { poore death, nor yet canst thou kill me. } \\
\text { From rest and sleepe, which but thy pictures bee, Much pleasure, } \\
\text { then from thee, much more must flow, And soonest our best } \\
\text { men with thee doe goe, } \\
\text { Rest of their bones, and souls deliverie. } \\
\text { Thou art slave to Fate, Chance, kings, and desperate men, And } \\
\text { dost with poyson, warre, and sicknesse dwell, } \\
\text { And poppie, or charmes can make us sleepe as well, And better } \\
\text { then thy stroake; why swell'st thou then; One short sleepe past, } \\
\text { wee wake eternally, } \\
\text { And Death shall be no more, death thou shalt die! }\end{array}$ \\
\hline
\end{tabular}

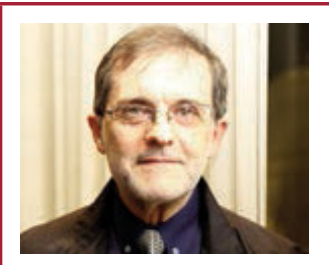

Oscar Bottasso es Investigador Superior de CONICET y del Consejo de Investigaciones de la Universidad Nacional de Rosario, Director del Instituto de Inmunología Clínica y Experimental de Rosario (UNR-CONICET). 